\title{
Linked Coding: A Qualitative Investigation of the Impact of a College Transition Program
}

\section{Lauren Coleman-Tempel, Achievement \& Assessment Institute University of Kansas}

Meghan Ecker-Lyster, Achievement \& Assessment Institute University of Kansas

Limited college knowledge often impacts underrepresented students' ability to navigate the college setting, creating institutional barriers for these students once arriving on campus. Students who are first-generation, low-income, and/ or racial minority students have been shown to be less "college ready" than their peers. This discrepancy in preparedness can be conceptualized as a cultural mismatch between the student's background knowledge and the higher education institution's expectations and norms (Lohfink \& Paulsen, 2005). This qualitative evaluation provides an in-depth investigation into first-generation, low-income, and minority students' perceptions and experiences with a yearlong college transition program. The study explores how a college transition program can impact students' social development.

Keywords: postsecondary transition, underrepresented students, qualitative methods

Entrance into and success in college can be one of the most important milestones in a student's life. As part of this process, students interact with many institutional "gatekeepers" such as professors, administrators, and advisors. In order to successfully engage with these critical figures during the transition process into postsecondary education, students must harness the unwritten codes of conduct that are expected in this setting (DiMaggio, 1982; Lareau, 2000, 2015; McDonough, 1997). Not all students are familiar with these unwritten expectations, which can lead to a cultural mismatch between the student and the postsecondary institution. Such a mismatch between student and institution is especially prevalent among student populations who 
are underrepresented in higher education, including students who are firstgeneration, low- income, and/or racial minorities (Lohfink \& Paulsen, 2005; Stephens, Brannon, Markus, \& Nelson, 2015).

A frequently cited intervention used to address cultural mismatch within higher education is the college transition program (e.g., Strayhorn, 2011; Tomasko, Ridgway, Waller, \& Olesik, 2016; Walpole, Simmerman, Mack, Mills, Scales, \& Albano, 2008). In general, the literature provides a great deal of descriptive information on transition programs; however, there are noticeably fewer studies examining the efficacy and impact of these programs on students' social development (Perna, 2002; Strayhorn, 2011; Swail \& Perna, 2002; Wibrowski, Matthews, \& Kitsantas, 2017). Even fewer studies directly investigate how transition programs develop the cultural capital (e.g., knowledge of campus resources) needed to successfully navigate the postsecondary institution (Stephens, Hamedani, \& Destin, 2014; Stephens et al., 2015). Of the studies that do attempt to uncover the relationship between participation in transition programs and the development of cultural capital and social connectedness, the majority of studies examine summer bridge programs (Strayhorn, 2011; Walpole et al., 2008). To better understand how a yearlong college transition program can leverage services to enhance students' social development, this study uses cultural mismatch theory as the theoretical lens to understand the importance and impact of a college transition program.

To better understand how college transition programs can impact the dynamic interaction between a postsecondary institution's cultural norms and students' development of the capital needed to succeed, this study employed a qualitative technique called linked coding. Linked coding was originated within the field of evaluation (Jackson \& Kolla, 2012), and is designed to quantify the context (C), mechanism (M), and outcomes (O) of a program's impact. Jackson and Kolla (2012) sought to develop a technique capable of explicitly coding the links between the CMOs into dyads and triads. The primary goal of the technique is to elicit meaningful findings by examining the social reality in which program outcomes are produced (Pawson \& Tilley, 1997). As such, linked coding provides researchers the ability to use participants' narratives to extrapolate conclusions about interactions between the context surrounding a program's implementation, the intervention mechanisms used to drive outcomes, and the actual outcomes that were produced. 
Further, this method has the potential to reach beyond traditional thematic analysis by producing an explicit link between a program's mechanisms and outcomes, allowing researchers to better understand programmatic impacts on participant development. The purpose of this study was to expand the literature on college transition programs' impact on students' social development. This study provides an in-depth examination of students' perceptions of the transition program.

\section{Theoretical Framework}

The social class achievement gap has perplexed the higher education system in the United States for decades. Research demonstrates that students from more affluent backgrounds persist and graduate at higher rates than their peers from lower-income families (Day \& Newburger, 2002; Reardon, 2011). A common explanation for this achievement gap is that there are differences in students' early socialization experiences. Research indicates that students from middle- and upper-income families are more likely to encounter educational nuances, and as a result are better positioned to navigate the higher education system (Bowen, Kurzweil, \& Tobin, 2005; Oyserman \& Destin, 2010). By contrast, the limited exposure to these educational nuances among lowerincome families can create a cultural mismatch. Scholars argue that without an intentional intervention designed to promote a cultural match, postsecondary institutions will exacerbate class inequalities (Hout, 2012; Lareau, 2015). It was the goal of the transition program in this study to remediate this cultural mismatch by providing targeted service for incoming marginalized students.

\section{Cultural Mismatch Theory}

At the foundational level of Cultural Mismatch Theory (Stephens, Fryberg, Markus, Johnson, \& Covarrubias, 2012), there exist three claims that are necessary to understand before applying this theory to any program model. The first claim of this theory is that university culture reflects the pervasive middle-class norms of independence that undergird mainstream U.S. society. Examples of the norms of independence that are rewarded by the university are the proclivity to find a fulfilling major through independent study or the idea of self-promotion. The second claim of this theoretical framework is that this focus on independent cultural norms at the university undermines 
certain groups of students whose cultures emphasize interdependence (e.g., first-generation students). The final claim is that this mismatch results in lower academic achievement among students from interdependent cultures and lower persistence of groups that do not fit the predominately White, middle-class norms. This study utilizes the assumptions outlined in Cultural Mismatch Theory as a key explanation as to why college transition programs are necessary for historically underrepresented students' success at PWIs (Predominately White Institutions).

\section{Cultural Capital}

Within Cultural Mismatch Theory, cultural capital is a major construct that warrants further discussion to help elucidate an operational definition. Cultural capital is described as habits or dispositions that are inherited from one's family or social class position (Bourdieu \& Passeron, 1979). Cultural capital can bolster academic achievement within higher education and takes the form of knowledge about the college landscape, including faculty-student interactions (Anderson \& Williams, 2018; Bourdieu \& Passeron, 1979). Unfortunately, this capital is often unequally distributed throughout society and can result in the creation of exclusive opportunities and advantages to those who possess them (Lareau, 2015).

The successful navigation of universities often requires the use of a distinct set of competences (e.g., campus knowledge, self-advocacy, institutional understandings). Researchers have highlighted the ways in which a cultural match can secure advantages for middle- and upper-class students (Dumais \& Ward, 2010; Yee, 2014). Examples of how these advantages are secured could be: asking for clarification on confusing or complex institutional regulations, utilizing campus resources to bolster academic achievement, or even asking for special considerations from faculty or staff such as extensions on deadlines. Interactions with university staff require a level of background knowledge and even coaching from parents or guardians who have attended college themselves. As a result of higher education's complexities, students from middle- and upper-class backgrounds use their cultural capital to accommodate their needs, while students from low-income backgrounds do not (Calarco, 2014; Lareau, 2015; Lareau, Weininger, \& Cox, 2018). The activation of cultural capital aligns with traditional norms of independence accepted in the university setting and carried by continuing-generation students. 


\section{Social Connectedness}

An extensive body of research identifies the positive benefits associated with social connectedness. Yet, there is concern regarding the use of social connectedness within the research literature due to inconsistencies in how it is conceptualized. While the current body of literature offers key insights into the impact of social connectedness on quality of life, Shaw and Chin-Newman (2017) raise concerns regarding how researchers define social support systems. To address this concern, the current study limited the scope of social connectedness to social systems directly accessible and related to a college campus (e.g., peer networks, faculty interactions, etc.). While family support systems have been identified as a key support for underrepresented college students (Hall, McNallie, Custers, Timmerans, Wilson, \& VandeBulck, 2016), the focus of this transition program was to connect students to on-campus supports.

Higher levels of social connectedness have been linked to positive physical and psychological health outcomes (Causey, Livingston, \& High, 2015; Evans, 1999; Hale, Hannum, \& Espelage, 2005; Khallad \& Jabr, 2015; Ozbay et al., 2007). Students who report more social connections experience less stress (Lafeniere \& Ledergwood, 1997) and report higher life satisfaction (Matsuda, Tsuda, Kim, \& Deng, 2014). Social integration into college life has been found to be a key factor impacting whether or not a student decides to persist in higher education (Covarrubias, Gallimore, \& Okagaki, 2018; Strayhorn, 2011). Unfortunately, not all students report and experience the same levels of social connectedness on a college campus. For instance, Walpole and colleagues (2008) found that students from lower socioeconomic (SES) backgrounds reported fewer interactions with faculty members and tended to be less involved in campus activities compared to their peers from higher SES backgrounds. It is likely that the cultural mismatch experienced by this population of students directly impacts their comfort with social interactions on college campuses. These findings are particularly troubling given the wealth of positive benefits associated with more social interactions and connections.

\section{Study Purpose}

Historically, colleges and universities have utilized college transition programs as a vehicle for assisting incoming first-year students with the academic transition process into higher education (Bir \& Myrick, 2015; 
Pascarella \& Terenzini, 2005; Walpole et al., 2008). Most programs target academically underprepared students, or students who are conditionally admitted to the institution (Walpole et al., 2008). For these types of transition programs that have a specific focus on enhancing academic readiness, it is logical to rely on academic growth and achievement indicators as markers of success. For example, a large body of research examines the impacts of participation in a transition program on academic outcomes such as GPA, credit accumulation, and persistence rates (Barnett et al., 2012; Harackiewicz, Canning, Tibbetts, Priniski, \& Hyde, 2016; Kallison \& Stader, 2012; Maton, Hrabowski, \& Schmitt, 2000; Strayhorn, 2011). Despite this large body of research there have been inconsistent findings regarding the influence transition programs have on academic achievement (e.g., Evans, 1999; Walpole et al., 2008). If universities want to fully examine and understand the impact of transition programs, it is important that research move beyond traditional academic indicators as measures of success, and begin to unpack the influence these programs have on students' overall development, including their cultivation and activation of cultural capital and social connectedness.

The purpose of this study was to extend the literature on college transition programs by focusing on how students' cultural capital and social connectedness are impacted by transition programs. This study applied a qualitative methodology (i.e., linked coding; Jackson \& Kolla, 2012) to identify and examine the interactions between the context of being a historically underrepresented student at a PWI, the uptake of the college transition program's intervention mechanisms, and programmatic outcomes that were produced. The study was designed to provide a robust description of participants' perceptions of the program, as well as a deeper understanding of the complexity surrounding the social reality in which college transition programs are conducted (Stolle-McAllister, Domingo, \& Carrillo, 2011). The study was guided by the following research questions:

1. How were student participants' levels and activation of cultural capital impacted by the college transition program?

2. How was student participants' sense of belonging impacted by the college transition program? 


\section{Methods: Participants \& Program Overview}

Eighty-six first-year students from historically underrepresented backgrounds (i.e., first- generation, low-income, and/or minority) participated in the college transition program. Incoming students who were U.S. Citizens or Permanent Residents and were first-generation, low-income, had a documented disability, and/or minority status were eligible to participate. First-generation was defined as students whose parents did not earn a bachelor's degree, low- income was defined as students who were eligible for a Pell grant, a documented disability included students with physical and mental health impairments, and minority status included any student who did not identify as White. All incoming students who were eligible were sent a recruitment email between late spring and early summer inviting them to participate in the transition program.

Table 1. Demographic overview of the study's sample.

Variables

Age

18

19

\section{Gender}

Male

Female

Living Arrangement

On-Campus

Off-Campus

Took Dual Credit in High School

Yes

No
Currently Involved in Campus Clubs

Yes

No

Currently Employed

Yes

No

Total number of participants
$\mathbf{N}$

6

5

2

9

10

1

6

5

$55 \%$

$45 \%$ 7

4

$64 \%$

\section{Percentage}

$55 \%$

$45 \%$

$18 \%$

$82 \%$

$91 \%$

$9 \%$

$36 \%$

8

$73 \%$

3

$27 \%$ 
The transition program that was evaluated in this study was housed at a public, four-year PWI and began in August 2017. The program was at no cost to the student and started with a five-day residential camp prior to the start of fall classes. Students who participated in the program were allowed to move into their residence hall assignments early. During the five-day residential portion of the program, students were required to attend informational sessions and workshops during the day and social networking and teambuilding activities during the evenings. The informational sessions and workshops were designed to familiarize students with campus resources (e.g., financial aid services) and college life (e.g., interacting with professors). Social networking and group activities were designed to foster a sense of community and social connectedness among participants (e.g., team building, recreational games). College access professionals (e.g., TRIO staff) and peer student leaders staffed the program. Use of peer student leaders was an intentional design of the program intended to foster peer connections among participants and current university students. Peer student leaders were former participants of the program and shared similar backgrounds as incoming participants. As part of the program, students were assigned to a college access advisor and peer student leader, both of whom provided structured advising, mentoring, and follow-up services throughout the academic year. Finally, all students who participated were required to enroll in the University's first-year seminar course.

\section{Pilot Study}

To understand the perceptions and impact of the college transition program on students' social development, researchers conducted three pilot focus groups to test and refine the study protocol questions in October 2017. Focus group protocols were centered around two key constructs outlined in the literature review: cultural capital and social connectedness (Strayhorn, 2011, 2012; Yoon, Lee, \& Goh, 2008). The pilot study served as a preliminary check and provided key information about the face validity and clarity of the target constructs. As previously mentioned, all transition program students were required to participate in a first-year seminar course. Researchers received permission from two first-year seminar instructors to come into their class and solicit participants for the focus groups. All of the pilot focus group sessions were conducted during class time and students who opted not to 
participate were excused from that class. All students who were present on the days when the focus groups occurred volunteered to stay and participate in the session. Seventeen students in groups of five to six participated in the pilot focus groups.

Results of the pilot study indicated confusion by participants about what it meant to be socially connected on campus. Protocol questions were revised based on the experience and feedback. The pilot study also revealed that a focus group format did not facilitate meaningful dialogue or elicit rich descriptions on how students perceived their development of cultural capital and social connectedness on campus. It was apparent during the focus group sessions that students were cautious with their responses, and the more reserved students appeared to gauge the reactions of their peers throughout the session. This may have limited their participation and feedback. For these reasons, the researchers revised the study's procedures to include individual interviews for a January 2018 follow-up session. It seemed that the one-onone interviews addressed the obstacles encountered during the pilot study. The one-on-one format appeared to provide a conducive outlet for students to explore sensitive topics.

\section{Procedures}

In January of 2018, researchers contacted by email the seventeen students who participated in the fall pilot study to invite them to participate in a follow-up one-on-one interview. The same seventeen students were solicited for the final study because this allowed students an opportunity to expand on similar questions asked during the pilot study, which allowed researchers a deeper understanding of the transition process. This also allowed researchers an opportunity to corroborate student response patterns from fall to spring. In general, student response patterns were similar across the two time periods, but the responses provided during the individual interviews in the spring contained much more detail about specific experiences.

Of the seventeen students contacted, eleven students responded to the invitation. The final sample was representative of the overall college transition program's demographic composition. Interviews lasted approximately 60 minutes, were audio recorded, and transcribed verbatim. No personally identifying information was linked to individual interviews, and all 
transcriptions were anonymized using pseudonyms. Participants were asked to reflect on their experiences and perceptions of the college transition program (e.g., What specific [transition program] experiences have helped you transition to life at [campus name]?). Participants were asked to share their experiences navigating the college campus (e.g., What on-campus resources have you accessed?). Finally, participants were asked about their social development (e.g., How would you describe your social networks on campus?). Transcriptions were uploaded into Dedoose, an online software program used to organize and code qualitative data. Two researchers coded the transcripts using techniques outlined by Jackson and Kolla's (2012) Linked Coding technique. The researchers met periodically to come to consensus on definitions and code structures, a step that has been shown to improve the reliability and validity of researchers' interpretation of data by ensuring a consistent understanding of the concepts which are being coded (Maxwell, 2012).

Researchers created and identified codes using a linked coding framework. Specifically, researchers organized transcripts into strings of dyad (e.g., CM, MO, CO) and triad (e.g., CMO) codes, where statements related to contexts (C), mechanisms (M), and outcomes (O) were given a discrete code. Based on recommendations by Jackson and Kolla (2012), researchers coded phrases as a context when it described something that existed prior to the introduction to the program. For instance, student narratives about personal or institutional context such as coming from a small town, being shy, or having trouble making friends were coded as a context. Researchers coded mechanisms as drivers or program activities that led to a specific outcome (positive or negative). This designation allowed for factors (e.g., participation in campus clubs) outside predetermined programmatic elements to be illuminated as primary drivers. Finally, researchers coded outcomes if the phrase described a result specific to that student's experience. To separate outcomes based on the study's research questions, child codes were used to create subcategories, including cultural capital and social connectedness. Not all outcomes were linked to programming mechanisms, which allowed for a deeper look into the student's postsecondary experience as a whole. The following is an example excerpt coded into a CMO triad [mechanism outcome - context]:

The program itself helped introduce me to campus and to alleviate

that stress. It got me introduced to where I live right now in the 
scholarship hall, early on so I could get used to how it functions, because I wasn't really sure how it works, but I knew it worked different than

other halls. I got to meet my proctor and they were really nice. As highlighted above, this method captured the connections between participants' contextual variables (e.g., background characteristics), experiences with program intervention mechanisms (e.g., campus orientation), and program outcomes (e.g., increased comfort on campus).

Next, researchers generated mid-range hypotheses about which CMO dyads and triads should be the focus of a deeper investigation. Within the field of evaluation, mid-range hypotheses, a derivative of mid-range theories developed by Merton (1967), are used to generate hypotheses that integrate theory and empirical data (Pawson, 2008). The mid-range hypotheses for this study were derived from the literature review, the college transition program's goals, discussions between program staff and the researchers, and the frequency levels of each outcome occurrence within the dataset. The midrange hypotheses differ from traditional hypotheses due to the nature of their origins, which are rooted in multiple levels of data. Traditional hypotheses do not take into account the frequency of levels of each outcome occurrence link. Three mid-range hypotheses emerged from this step:

- The transition program will increase participants' comfort interacting with "gatekeepers" (e.g., university faculty) on campus.

- The transition program will provide a social network in which students can develop a sense of community and social connectedness.

- The transition program will increase students' cultural capital, including campus knowledge, and thereby increase their ability to navigate campus resources.

Third, researchers re-examined the data to understand how it bolstered the mid-range hypotheses. Researchers examined the high-frequency CMO dyads and triads to identify patterns and emerging themes. Researchers were able to examine themes around the contextual factors, program mechanisms, and outcomes without disrupting the natural story-telling process (Jackson \& Kolla, 2012). Further, this process allowed researchers the ability to understand the degree to which the various CMO strings directly identified by participants converged with the formal research literature and theory (Jackson \& Kolla, 2012). 
Finally, multiple measures were taken to ensure trustworthiness of data. Member checks were conducted with two randomly selected interviewees to ensure accuracy of transcription and interpretation. This method of respondent validation is a cornerstone of qualitative validity (Bryman, 2006; Maxwell, 2012). The interview data reached saturation after approximately six interviews, suggesting consistency of participant interpretation of programming. Researchers also conducted inter-coder reliability checks by cross-coding two randomly selected interviews and consulting one another with discrepancies until consensus was met.

\section{Findings}

The following section outlines the findings from the follow-up individual interviews that were conducted in the spring. Researchers examined the strings of CMO dyads and triads. Researchers identified high-frequency outcome dyads and triads, and examined the interaction between students' background contexts and program mechanisms as a driver of program outcomes. The following section is organized around the two key constructs under investigation - the impact of the college transition program on students' development and activation of cultural capital and social connectedness.

\section{Cultural Capital}

Resource knowledge. Seven of the eleven students interviewed were from small, rural towns across the Midwest. This contextual factor was repeatedly linked to both the anxieties of stepping onto a large campus and the usefulness of the program's mechanisms that allowed students to move into their residence halls one week prior to the start of classes. Many of the interventions during the pre-semester week focused on increasing participants' knowledge of campus resources. The study's results indicated that these mechanisms were especially beneficial for students from small towns. One of the most frequently cited program mechanisms was an activity called The Amazing Race, a campus-wide scavenger hunt led by peer leaders in small teams. The majority of interviewees connected their participation in the scavenger hunt to increased levels of comfort with the campus and institutional knowledge. The following excerpt is from an interview with a student from a small town: 
Anna: I have been here for a campus visit before, and then student orientation, but it was still huge because I was just in little parts. They would like put me on a bus and five minutes later I'd be somewhere and I didn't know where I was. I think [the transition program] helped make [the university] feel smaller than it actually is. With friends, sometimes I know where stuff is and they don't. And I'm like, "how do you not know?!" Next, data suggested that the uptake of resource knowledge led to an increase in participants' utilization of campus services. Students recalled using multiple campus resources because they had gained a greater understanding of the service offerings as well as the location of those offices on the large campus during the first week of the transition program. One student, Angela, credited the program's resource presentations with her non-academic development during her first year, "...I have been able to use lots of resources on campus because I knew they existed. Whether it be I'm trying to build my resume for certain applications or take advantage of certain things that are offered on campus, I've really been able to utilize those resources. [The program] opened those up to us. That's been really nice."

As a result of increased campus resource knowledge, participants said they felt like an expert among their peers. More than half of the students began their first week of classes feeling like they knew much more about the campus than their classmates. Students reported that this increased knowledge gave them an increased sense of connectedness and comfort on campus. Alejandra indicated that she felt like she already went through the tough phase of the transition process prior to the start of classes:

I would say [the program] affected [the transition to college] a lot. Like the first week is obviously a little scary for any freshman and I was already kind of used to the building where I was staying and the food and how the card worked, where to go. So, I think it really helped to give me information that I needed, that I otherwise wouldn't have gotten. Other freshmen who didn't do [the program] were lost. I found myself answering questions for other students because I knew the answers thanks to [the program].

Comfort interacting with faculty and staff. There were mixed results regarding the transition program's impact on student and faculty/staff 
interactions. Participants reported that their initial hesitations to interact with faculty were pacified by the Faculty Question and Answer (Q\&A) Panel. Students reported feeling reluctant to interact with professors prior to coming to campus and said they found the Q\&A Panel particularly helpful in making faculty appear more approachable. Anna referenced the fact that the instructors on campus "all have a PhD," which makes interactions with them intimidating. Another student worried about how she would be perceived in a face-to-face interaction because she is "socially anxious." Anna cited the Q\&A Panel as a rich insight into what professors expect of students since she did not foresee herself going out on a limb to interact with them:

I really liked the teacher panel. We got to ask questions...They had professors sitting, and we got to ask them what's the deal with our laptops, and they would say, "it depends on your professor." And I would be like, "oh each professor is different?" That was like "oh wow! They're all different, I'm not in high school anymore!” but it's all regulated. Each professor has their own thing. That kind of just reminded me that I'm no longer in high school.

While the data demonstrated positive results regarding an immediate increase in students' self- reported comfort levels interacting with faculty, many students reported that this increased comfort did not sustain. The majority of students said they did not interact with faculty during the fall semester because they still felt intimidated. Several students hypothesized that their comfort interacting with professors would likely increase over the years as they become more advanced students. Approximately one-third of the students referenced being a first-year student as the context surrounding their lack of comfort speaking with professors.

One student saw Graduate Teaching Assistants (GTA) as a stepping stone in building her comfort level interacting with professors. Although the student reported feeling intimidated by her professor, as well as strong feelings of being seen as unimportant to her professor (she said the professor did not respond to her emails), she saw the GTA as a viable alternative for getting her questions answered. The GTA functioned as an important mechanism outside of the transition program that increased the level of comfort felt by program participants.

In addition to the GTAs, students also reported feeling comfortable interacting with the support staff on campus, specifically their assigned TRIO advisor. As previously stated, students who participated in the college 
transition program were also admitted to the TRIO Student Support Services program. As part of the TRIO program, students had access to advising, mentoring, and follow-up services throughout the academic year. One of the prominent features of the college transition program was the assignment of all students to a Student Success Specialist (SSS). This program mechanism was linked to many positive outcomes, particularly during difficult times for students. When asked about elements of the program, Olivia, a student having a difficult time transitioning, referenced her SSS as an important stabilizing force:

Olivia: Yeah, like towards the end of last semester I was kind of going through a lot of stuff with my family and school, and some of the professors noticed and [my SSS] brought me in and talked to me. She just reassured me that she is there. And that I'm not alone.

\section{Social Connectedness}

In developing a concept for how students from underrepresented backgrounds define what it means to be socially connected, researchers asked participants to specifically reflect on what it means to them to belong on the campus. Responses included hanging out with friends, being in clubs, and attending sporting events. The data suggested variations in how social networks are formed based on individuals' background characteristics. Multiple women of color explained that those who fit in most on this campus were students who came with established peer groups and those who rushed the predominately White Greek system. When one participant was asked if she feels more or less connected than her peers, Janessa responded:

I feel like it might depend, because there are the Greek life people who are really connected, and there are students who aren't or who are like me who came up here not knowing a lot and I didn't rush. People might not have gone out of their comfort zone to make connections. I was probably on a smaller scale of those who did.

With these preconceived notions of who belongs and who does not, students were clear that being around other students "like them" mattered tremendously. Rubi, a student of color, stated:

I would say for the most part people who live in [residence halls], I feel

like most of them are White and sometimes I'll be like eating and I'll walk 
in and my floor is mostly people who rushed or in sororities. There's maybe five of us on the floor who are colored.

Later when asked when she feels like she is a part of the university, Rubi explained:

When I'm with those people [other students in multicultural clubs or transition program participants], yes. When I'm participating in the clubs and am doing stuff, yes. There are times that maybe you're in a class and maybe I'm one of three people who are colored on the bus and there's no one of color on the bus. But yeah for the most part I think I do feel like I am a part of [the university] and I know that I earned my spot here in all my classes and I know that I belong here.

Researchers noted a link between the context of being a woman of color at a PWI to the transition program's club presentations that introduced participants to on-campus clubs which catered to students from similar backgrounds, including the multicultural club. The multicultural club was a frequently cited outlet where students of color reported feeling socially connected. This finding implied this particular program component was particularly useful in developing participants' social connection to campus, particularly among female students of color in this study. Students said that the presentations surrounding these clubs created a necessary outlet for them to connect with other students from underrepresented backgrounds and to engage in activities where they were able to increase their feelings of belonging on campus.

Several students interviewed in this study indicated that they had come to campus without knowing anyone. Participants said that coming to campus alone gave them an opportunity to create a new network of peers. However, despite this excitement, most students said this also created a lot of anxiety. Students indicated that without mechanisms in place to ensure opportunities to meet students from similar backgrounds they would have felt like an outsider. Data suggested that students who came into the program not knowing anyone or being from out- of-state benefitted the most from the program activities designed to increase social connections. The majority of these students referenced the program's team component as a beneficial piece of the program. This mechanism created teams of students by grouping them based on residence hall assignments, thus establishing a network of 
peers upon arrival. Data suggested that this approach to team building was associated with positive social outcomes. In reflecting on his experience, Jacob stated:

I usually just hang out with the same people, but they're the people who are on my floor in my dorm. Most of them were in [the transition program] ...I'm from out-of-state so I didn't know who anyone was. It would've been really difficult to talk to those people and come up to them and tell them who I am. I know a couple people who didn't go through [the program] and they say they wish they would've because us who are in [the program] had an easier time finding connections.

Third, a major component of the transition program was the inclusion of peer leaders. Peer student leaders held regular office hours and reached out to the transition program participants periodically throughout the year with information about activities and financial aid deadlines. This component reflected mixed outcomes in the data, ranging from one student who formed a very strong social tie that was carried over into the spring semester to other students who had no contact after the pre-semester residential component ended. When examining this program component, it was apparent that the success of the near-peer mentoring hinged on the personal connections and relationships that were (or were not) developed between the participants and peer leaders. The majority of participants who cited this program mechanism as being successful referred to their informal interactions with the peer leader as a key driver to the success of the mechanism. The following student, referencing the peer leader component, noted the comfort of being with someone closer to her age:

Jessie: Student leaders. If you had a question they would answer, or they would just like...they were just like students - just like you. I didn't have to talk formally; I could be comfortable around them.

Megan, a student with a very strong connection with her peer leader, reflected on how formal and informal time spent with her peer student leader helped her:

I remember it was after [the residential component] was over and my peer leaders were at my dorm with our group of people and we just like watched a movie. I don't know, it was just fun to hang out without talking about anything. And then from there, the office hours were happening and one of my peer leaders is super good at math. I don't know, just 
helping each other with things that we're struggling with. You know, just expressing frustrations can help the relationship develop more than what may have happened during the actual week of [the residential component].

Nevertheless, the link between the outcome of social connectedness and the mechanism of placing peer leaders on every team was not as robust as program staff had intended. The following student, while recognizing the utility of the service, could not point to a specific reason for not using the peer leader program component:

Anna: I would have, but for me I didn't really need it. It would've been helpful if I used it more, though. I know that one of our leaders is really good with math and I could've used that as well because he's really good. I just didn't. It would've been helpful to just sit and talk to them and work on homework with him or with a little group. I just felt like I didn't need it at the time. But looking back I should've used it.

\section{Discussion}

The findings from this study suggest that college transition programs can serve as a vehicle for fostering historically underrepresented students' social development, including enhancing the development of cultural capital and social connectedness. Students reported increased campus knowledge, navigational skills, and exposure to peers from similar backgrounds as primary outcomes of participation. The findings produced by this investigation are consistent with multiple streams of research that indicate confidence in navigating campus resources is a key factor which leads to a successful transition into college (Covarrubias et al., 2018; Strayhorn, 2011). For several students in this study, this familiarity translated into a stronger self-reported confidence and sense of social connection on campus. Namely, students said they felt like experts who could assist other incoming first-year students who did not participate in the program with navigating campus resources.

Research suggests that the more comfortable a student feels interacting with faculty and staff, the more likely a student is to have a successful transition into college (Dumais \& Ward, 2010; Perez \& McDonough, 2008). The college transition program attempted to increase students' comfort with faculty by offering a Faculty Q\&A Panel during the first week of the 
program. The results of the panel were mixed. Students reported that the panel enhanced their understanding of faculty expectations, as well as their self-reported comfort levels during the first week of the program. However, the panel did not result in high engagement with faculty during the semester. The majority of students reported little to no interactions with their faculty instructors during the fall semester. Many students said they still did not feel comfortable with these interactions. This finding is not surprising, given that reluctance of historically underrepresented student populations to interact with faculty has been cited in several other studies as well (Collier \& Morgan, 2008; Inkelas, Daver, Vogt, \& Leonard, 2007). The efficacy of the Faculty Q\&A Panel demonstrated promising initial results in terms of changing students' perceived comfort levels, however, to sustain these effects programs may need to provide supplemental activities centered on faculty interaction throughout the semester. These activities should be a structured interaction between students and faculty that are outside of the classroom.

While the results regarding faculty interactions were limited, there were stronger results around students' willingness to interact with campus support staff. One student reported that GTAs are a great alternative to the professor when seeking assistance with specific class-related questions and materials. While GTAs were not a specific component endorsed or sponsored by the college transition program, this finding offers an important avenue college transition staff can explore for future program planning (Calarco, 2014; Lareau, 2015). Students also identified their TRIO Student Success Specialist as another information source they felt comfortable accessing. This finding suggests that intentionally assigning an on-campus advocate for students is a beneficial strategy to reduce students' anxiety interacting with campus staff. It is likely that the individually-assigned SSS allowed students the opportunity to develop a stronger connection with a specific individual on campus, thus reducing the reluctance to seek information from someone they did not know. Future research should test the significance of these contextual factors to better understand why support staff were seen as more approachable than faculty among this population of students.

The overall development of students' social connections on campus were particularly contingent upon the contextual background factors of each student. For example, students who came into the program not knowing 
anyone or being from out of state benefitted the most from the program activities designed to increase social connections. Several students from similar backgrounds (e.g., being the only one to come to campus from their friend group, coming from out-of-state, etc.) indicated that the team-building activities (mechanism) were one of the most beneficial aspects of the program. These students cited strong, lasting social connections that were made as a result of participating in the program. These findings are in line with previous research highlighting the importance of social ties as drivers of success for college students (Covarrubias et al., 2018; Strayhorn, 2011). Based on this finding, it is recommended that transition programs include team elements into their program design. Basing teams on common areas of interest (e.g., major) or residence hall assignment will help facilitate a more organic connection among participations. Further, assigning teams based on residence halls provides a natural opportunity for higher levels of exposure to one another because they will be likely living in the residence hall the entire academic year.

\section{Limitations and Future Research}

Although the results of this study suggest that the program was successful in cultivating cultural capital and social connectedness among participants, there are several limitations that must be considered when interpreting the results. First, this study highlights data that was generated from a program evaluation of one college transition program that occurred on one university campus. This single-campus design limits the generalizability of the findings, which is a frequently cited limitation of qualitative studies (Atieno, 2009). Researchers should consider applying this methodology and framework to a multi-site study of similar transition programs to better understand the variances in program outcomes by participants' contextual backgrounds and specific program mechanisms. Additionally, it is suggested that future research examining college transition programs' impact on the development of cultural capital and social connectedness employ a mixed methods approach. Incorporating quantitative methods into the investigation allows for an opportunity to test and confirm that the findings produced from this study are statistically significant and not due to chance. 
Second, it was clear from the student responses that the majority of students participated less in the college transition program after the first week of the program, which was the most intensive component of the program. Students were allowed to move onto campus one week prior to the start of classes, and during this week students experienced a highly structured schedule where they were surrounded by other program participants and staff. While this was a key component of the transition program, there were other program components that occurred throughout the academic year (e.g., first-year experience course, mandatory advising, peer leaders, etc.) that did not seem to get the same attention from the students. It was unclear if students realized that the advising sessions that occurred during the academic year were part of the transition program, as opposed to general university requirements for all first-year students. Future research should attempt to parse out the differential impacts of each specific program component to fully understand what active program ingredients are driving student development.

A third limitation that must be considered is the voluntary nature of the transition program. While the transition program was only available to incoming first-year students who met eligibility requirements (firstgeneration, low-income, documented disability, and/or minority status), the program was completely voluntary. As such, it is possible that students who elected to participate in the program differed from similar students who did not participate. Participants may have been more motivated and proactive in their transition process, which may suggest higher levels of baseline cultural capital and/or social connectedness than those who did not attend the program. In other words, the program participants may have already been better positioned for the transition process than their similar peers. As such, caution must be applied when interpreting these findings and drawing conclusions about the effects of the program.

Finally, the practical utility of the linked coding method should be considered, especially by practitioners looking to evaluate the impacts of their college transition programs. As noted in the original study (Jackson \& Kolla, 2012) and substantiated through the analytic process used in this study, linked coding is a time-consuming process. It is estimated that the linked coding analytic process took approximately 85 hours to complete. Due to the significant time commitment that this process required it may not be suited 
for busy practitioners who are looking for a method to quickly gauge the impact of their program on student development. Alternative methods, such as student surveys, may be a more feasible avenue to investigate program impacts and evaluate the usefulness of the program.

\section{Conclusion}

Student perceptions of the college transition program suggest the program was effective at developing the necessary cultural capital and social connectedness needed to succeed during the first year of college (Bir \& Myrick, 2015; Pascarella \& Terenzini, 2005; Walpole et al., 2008). The program helped participants build relationships and friendships with other participants, provided them the navigational skills necessary to access campus resources, and enhanced their ability to network and interact with campus support staff. As colleges continue to look for avenues to support the transition into higher education, effective methodologies are needed to understand the impact of these programs. This paper showcases a robust qualitative analytic that can be used to examine the impact of college transition programs on student development. Furthermore, this paper offers several student-driven suggestions to inform transition programs' service delivery model to better ensure a successful transition for all students. 


\section{References}

Anderson, P., \& Williams, J. (2018). Identity and difference in higher education: Outsiders within. London, UK: Routledge.

Atieno, O. P. (2009). An analysis of the strengths and limitations of qualitative and quantitative research paradigms. Problems of Education in the 21st Century, 13, 13-18.

Barnett, E. A., Bork, R. H., Mayer, A. K., Pretlow, J., Wathington, H. D., \& Weiss, M. J. (2012). Bridging the gap: An impact study of eight developmental summer bridge programs in Texas. National Center for Postsecondary Research.

Bir, B., \& Myrick, M. (2015). Summer Bridge's Effects on College Student Success. Journal of Developmental Education, 39(1), 22.

Bourdieu, P., \& Passeron, J. C. (1979). The inheritors: French students and their relation to culture. Chicago, IL: University of Chicago Press.

Bowen, W. G., Kurzweil, M. A., \& Tobin, E. M. (2005). Equity and excellence in American higher education. Charlottesville, VA: University of Virginia Press.

Bryman, A. (2006). Integrating quantitative and qualitative research: how is it done? Qualitative research, 6, 97-113.

Calarco, J. M. (2014). Coached for the classroom: Parents' cultural transmission and children's reproduction of educational inequalities. American Sociological Review, 79, 1015-1037.

Causey, S. T., Livingston, J., \& High, B. (2015). Family structure, racial socialization, perceived parental involvement, and social support as predictors of self-esteem in African American college students. Journal of Black Studies, 46, 655-677.

Collier, P. J., \& Morgan, D. L. (2008). "Is that paper really due today?”: differences in first- generation and traditional college students' understandings of faculty expectations. Higher Education, 55, 425-446.

Covarrubias, R., Gallimore, R., \& Okagaki, L. (2018). "I know that I should be here": Lessons learned from the first-year performance of borderline university applicants. Journal of College Student Retention: Research, Theory \& Practice, 20(1), 92-115. 
Day, J. C., \& Newburger, E. C. (2002). The big payoff: Educational attainment and Synthetic estimates of work-life earnings (Current Population Report P23-210). Washington, DC: U.S. Census Bureau.

DiMaggio, P. (1982). Cultural capital and school success: the impact of status culture participation on the grades of U.S. high school students. American Sociological Review 47, 89-201.

Dumais, S. A., \& Ward, A. (2010). Cultural capital and first-generation college success. Poetics 38, 245-265.

Evans, R. (1999). A comparison of success indicators for program and nonprogram participants in a community college summer bridge program for minority students. Visions, 2(2), 6- 14.

Hale, C. J., Hannum, J. W., \& Espelage, D. L. (2005). Social support and physical health: The importance of belonging. Journal of American College Health, 53, 276-284. doi: 10.3200/JACH.53.6.276-284

Hall, E. D., McNallie, J., Custers, K., Timmermans, E., Wilson, S. R., \& Van den Bulck, J. (2016). A cross-cultural examination of the mediating role of family support and parental advice quality on the relationship between family communication patterns and first-year college student adjustment in the United States and Belgium. Communication Research, 44, 638-667. doi: 10.177/009365021665775

Harackiewicz, J. M., Canning, E. A., Tibbetts, Y., Priniski, S. J., \& Hyde, J. S. (2016). Closing achievement gaps with a utility-value intervention: Disentangling race and social class. Journal of Personality and Social Psychology, 111, 745.

Hout, M. (2012). Social and Economic Returns to College Education in the United States. Annual Review of Sociology, 38, 379-400.

Inkelas, K. K., Daver, Z. E., Vogt, K. E., \& Leonard, J. B. (2007). Living-learning programs and first-generation college students' academic and social transition to college. Research in Higher education, 48, 403-434.

Jackson, S. F., \& Kolla, G. (2012). A new realistic evaluation analysis method: linked coding of context, mechanism, and outcome relationships. American Journal of Evaluation, 33, 339-349. 
Kallison, J. M., Jr., \& Stader, D. L. (2012). Effectiveness of summer bridge programs in enhancing college readiness. Community College Journal of Research and Practice, 36, 340-357.

Khallad, Y., \& Jabr, F. (2015). Effects of perceived social support and family demands on college students' mental well-being: A cross-cultural investigation. International Journal of Psychology, 50(5), 1-8. doi: 10.1002/ijop.12177

Lafeniere, K. D., \& Ledergwood, D. M. (1997). Influences of leaving home, perceived family support, and gender on the transition to university. Guidance \& Counseling, 12(4), 14-18.

Lareau, A. (2000). Home advantage (2nd ed.). Lanham, MD: Rowman and Littlefield.

Lareau, A. (2015). Cultural knowledge and social inequality. American Sociological Review, 80(1), 1-27.

Lareau, A., Weininger, E., \& Cox, A. (2018). Parental Challenges to Organizational Authority in an Elite School District: The Role of Cultural, Social, and Symbolic Capital. Teachers College Record, 120(1), n1.

Lohfink, M. M., \& Paulsen, M. B. (2005). Comparing the determinants of persistence for first generation and continuing-generation students. Journal of College Student Development, 46, 409-428.

Maton, K., Hrabowski, F., \& Schmitt, C. (2000). African American college students excelling in the sciences: College and post college outcomes in the Meyerhoff Scholars Program. Journal Of Research In Science Teaching, 37, 629-654.

Matsuda, T., Tsuda, A., Kim, E., \& Deng, K. (2014). Association between perceived social support and subjective well-being among Japanese, Chinese, and Korean college students. Psychology, 5, 491-499.

Maxwell, J. A. (2012). Qualitative research design: An interactive approach (Vol. 41). Sage.

McDonough, P. M. (1997). Choosing colleges: How social class and schools structure opportunity. Albany, NY: State University of New York Press. 
Merton, R. (1967). On sociological theories of the middle-range. In R. Merton (Eds.), On Theoretical Sociology: Five essays old and new. New York: Free Press.

Oyserman, D., \& Destin, M. (2010). Identity-based motivation: Implications for intervention. The Counseling Psychologist, 38, 1001-1043.

Ozbay, F., Johnson, D. C., Dimoulas, E., Morgan, C. A., Charney, D., \& Southwick, S. (2007). Social support and resilience to stress. Neurobiology to Clinical Practice, 4(5), 35-40.

Pascarella, E. T., \& Terenzini, P. T. (2005). How college affects students: Volume II, A third decade of research. San Francisco, CA: Jossey-Bass.

Pawson, R. (2008). Middle range theory and program theory evaluation: From provenance to practice. In F. Leuuw \& J. Vassan (Eds.), Mind the gap: Perspectives on policy evaluation and the social sciences. New York, NY: Routledge.

Pawson, R., \& Tilley, N. (1997). Realistic evaluation. Thousand Oaks, CA: Sage Publications.

Perez, P. A., \& McDonough, P. M. (2008). Understanding Latina and Latino college choice: A social capital and chain migration analysis. Journal of Hispanic Higher Education, 7, 249-265.

Perna, L. W. (2002). Precollege outreach programs: Characteristics of programs serving historically underrepresented groups of students. Journal of College Student Development, 43, 64-83.

Reardon, S. F. (2011). Whither Opportunity? Rising Inequality, Schools, and Children's Life Chances. New York, NY: Russell Sage Foundation.

Shaw, S. T., \& Chin-Newman, C. S. (2017). "You can do it!" Social support for transfer students during the transition from community college to four-year university. Journal of First- Year Experience \& Students in Transition, 29, 65-78.

Stephens, N. M., Brannon, T. N., Markus, H. R., \& Nelson, J. E. (2015). Feeling at home in college: Fortifying school-relevant selves to reduce social class disparities in higher education. Social Issues and Policy Review, 9(1), 1-24. 
Stephens, N. M., Fryberg, S. A., Markus, H. R., Johnson, C., \& Covarrubias, R. (2012). Unseen disadvantage: How American universities' focus on independence undermines the academic performance of firstgeneration college students. Journal of Personality and Social Psychology, 102, 1178-1197.

Stephens, N. M., Hamedani, M. G., \& Destin, M. (2014). Closing the social-class achievement gap: A difference-education intervention improves first-generation students' academic performance and all students' college transition. Evanston, IL: Northwestern University Associate for Psychological Science.

Stolle-McAllister, K., Domingo, M., \& Carrillo, R. (2011). The Meyerhoff way: How the Meyerhoff Scholarship Program helps black students succeed in the sciences. Journal of Science Education and Technology, 20(1), 5-16.

Strayhorn, T. L. (2011). Bridging the pipeline: Increasing underrepresented students' preparation for college through a summer bridge program. American Behavioral Scientist, 55, 142-159.

Strayhorn, T. (2012). College students' sense of belonging: A key to educational success for all students. New York; NY: Routledge.

Swail, W. S., \& Perna, L. W. (2002). Pre-college outreach programs: A national perspective. In W. G. Tierney \& L. S. Hagedorn (Eds.), Increasing access to college: Extending possibilities for all students (pp. 15-34). Albany, NY: State University of New York.

Tomasko, D. L., Ridgway, J. S., Waller, R. J., \& Olesik, S. V. (2016). Association of summer bridge program outcomes with STEM retention of targeted demographic groups. Journal of College Science Teaching, 45(4), 9099.

Walpole, M., Simmerman, H., Mack, C., Mills, J., Scales, M., \& Albano, D. (2008). Bridge to success: Insight into summer bridge program students' college transition. Journal of the First-Year Experience \& Students in Transition, 20(1), 11-30. 
Wibrowski, C. R., Matthews, W. K., \& Kitsantas, A. (2017). The role of a skills learning support program on first-generation college students' selfregulation, motivation, and academic achievement: A longitudinal study. Journal of College Student Retention: Research, Theory \& Practice, 19, 317-332.

Yee, A. (2014). Major decisions: How social class shapes undergraduate achievement. University of Pennsylvania, ProQuest, UMI Dissertations Publishing, 362-367.

Yoon, E., Lee, R. M., \& Goh, M. (2008). Acculturation, social connectedness, and subjective well-being. Cultural Diversity and Ethnic Minority Psychology, 14, 246. 